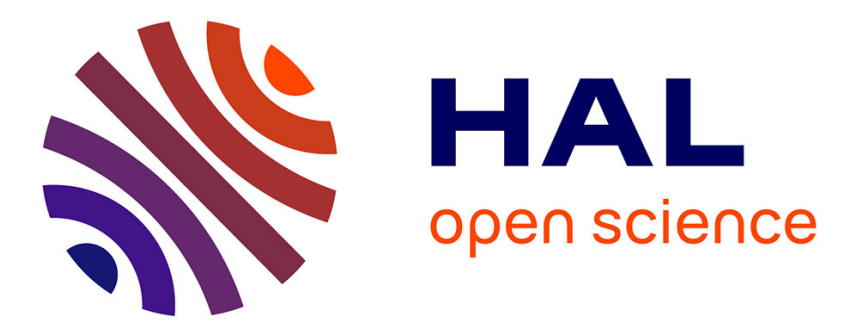

\title{
Combined Biological and Modeling Approach of Hematopoiesis: From Native to Stressed Erythropoiesis
} Céline Bonnet, Panhong Gou, Simon Girel, Vincent Bansaye, Catherine Lacout, Karine Bailly, Marie-Hélène Schlagetter, Evelyne Lauret, Sylvie Méléard, Stéphane Giraudier

\section{To cite this version:}

Céline Bonnet, Panhong Gou, Simon Girel, Vincent Bansaye, Catherine Lacout, et al.. Combined Biological and Modeling Approach of Hematopoiesis: From Native to Stressed Erythropoiesis. SSRN Electronic Journal, In press, 10.2139/ssrn.3777468 . hal-03379966

\section{HAL Id: hal-03379966 https://hal.science/hal-03379966}

Submitted on 15 Oct 2021

HAL is a multi-disciplinary open access archive for the deposit and dissemination of scientific research documents, whether they are published or not. The documents may come from teaching and research institutions in France or abroad, or from public or private research centers.
L'archive ouverte pluridisciplinaire HAL, est destinée au dépôt et à la diffusion de documents scientifiques de niveau recherche, publiés ou non, émanant des établissements d'enseignement et de recherche français ou étrangers, des laboratoires publics ou privés. 
Combined biological and modelling Approach of Hematopoiesis: From Native to stressed Erythropoiesis.

Céline Bonnet*3, Panhong Gou*1, Simon Girel ${ }^{3}$, Vincent Bansaye ${ }^{3}$, Catherine Lacout ${ }^{1}$, Karine Bailly $^{2}$, Marie-Hélène Schlagetter ${ }^{1}$, Evelyne Lauret ${ }^{2}$ Sylvie Méléard ${ }^{\$ 3,4}$, and Stéphane Giraudier ${ }^{\text {1. }}$.

*These two authors contribute equally to this work.

These three authors are co-last authors.

${ }^{1}$ Université de Paris, Hôpital Saint Louis, INSERM U1131, F-750 Paris, France

${ }^{2}$ Université de Paris, Institut Cochin, INSERM U1016, CNRS UMR8104, F-75014 PARIS, France

${ }^{3}$ CMAP, CNRS, Ecole polytechnique, Institut Polytechnique de Paris, 91128, Palaiseau.

${ }^{4}$ Institut universitaire de France

Short title: Modelling hematopoiesis from stem to red cells (50 characters)

Corresponding author: Stéphane Giraudier

Address: INSERM U1131, Centre Hayem, Hôpital Saint Louis, 1 avenue Claude Vellefaux, 75010 Paris, France Phone: +33 (0)1 Fax: +33 (0)1 e-mail: stephane.giraudier@aphp.fr Supported by grants from the INSERM and INCa 2018 and fellowships from The Research ministry of China.

Total word count: 3575 words

Abstract word count: 231 words

Abstract (150 words) 
We developed here a new mathematical modelling approach which reconciliates native and stress hematopoiesis, focused on hematopoietic stem and progenitor compartments. We first proposed an erythropoiesis model leaning on a minimum of 6 cell-amplification compartments, able to reproduce native erythropoiesis. A phenylhydrazine-induced hemolytic stress was next applied, and in vivo data were used to estimate model parameters through an optimized algorithm and integrated regulatory processes. A reduction of all stem cell compartments was observed, due to a drastic differentiation without proliferation during 7 days, followed by a huge proliferation in all compartments including long-term hematopoietic stem cells, before returning to normal values. The 6-compartment model applied to stress erythropoiesis was complexified by integrating regulatory processes. Thus, regulation of hematopoiesis appears dispensable during native hematopoiesis but mandatory for stress hematopoiesis. In conclusion this multi-step and time-dependent model of immature hematopoiesis opens new opportunities to understand development of normal or pathological hematopoiesis. 


\section{INTRODUCTION}

Hematopoiesis provides the lifelong supply of mature blood cells derived from a rare population of bone marrow (BM) multipotent hematopoietic stem cells (HSCs) (Orkin and Zon, 2008; Till and McCulloch, 2012). The lineage relationship between HSCs and mature cells was first proposed as a multistep process in which generations of diverse blood cells are coupled with movement through consecutive Hematopoietic Stem and Progenitor Cell (HSPC) amplification motors, from HSC to mature blood cells. HSPC division and differentiation are controlled by extracellular signals, and by intracellular networks. In the classical model, successive HSPC compartments, Long-Term HSC (LT-HSC), Short-Term HSC (ST-HSC), MultiPotent Progenitor (MPP), etc.. along hematopoietic differentiation process are defined on their immunophenotypic level, typically by the expression of cell surface marker combinations (Eich et al., 2019; Notta et al., 2016). In this context, since the 1960s, HSCs are typically functionally defined by their ability to sustain multi-lineage engraftment for an extended period of time upon serial transplantation into irradiated recipient mice (Till and McCulloch, 2012). Recently, new generation of experimental tools allowing in situ analysis of HSC output has challenged the classical model by pointing out fundamental differences between physiological unperturbed hematopoiesis and stress hematopoiesis (Busch et al., 2015; Carrelha et al., 2018; Chapple et al., 2018; Pei et al., 2017, 2020; Rodriguez-Fraticelli et al., 2018; Säwen et al., 2018; Sun et al., 2014). In particular, in native hematopoiesis, progenitors directly downstream of LT-HSCs (ST-HSC, MPP...) serve as a major, nearly self-renewing source of day-to-day hematopoiesis, rendering blood and immune system less dependent on LT-HSC, in agreement with the quiescence of adult LT-HSCs (Busch and Rodewald, 2016; Busch et al., 2015; Foudi et al., 2009; Schoedel et al., 2016). In addition, recent single cell profiling analysis has unveiled the tremendous heterogeneity of each previously defined compartment leading to a continuum in hematopoiesis process (Giladi et al., 2018; Laurenti and Göttgens, 2018; Paul et al., 2015; 
Velten et al., 2017). However, punctuated transitions across this continuous gene expression landscape may still exist and represent functionally distinct groups of cells (Liggett and Sankaran, 2020).

Mathematical modelling integrating both unperturbed and stress hematopoiesis should be a powerful approach to address key questions in hematopoiesis, able to provide qualitative and quantitative insights into stem cell dynamics and fate commitment. To date, most of hematopoiesis modelling is based on the existence of few cell compartments (stem cells, progenitors and mature cells) (Crauste et al., 2008, 2010). Rodewald's group has introduced a major breakthrough by modelling hematopoiesis based upon stem compartments from LT-HSC to MPP in unperturbed hematopoiesis (Busch et al., 2015). Nevertheless, they notice that their steady state model cannot recapitulate stress hematopoiesis such as 5-fluorouracile (5-FU) treatment, suggesting that unperturbed and stress hematopoiesis do not follow the same biological rules.

Here we want to recapitulate in a single mathematical model stress and steady-state hematopoiesis, based on in vivo experiments. We focused our attention on erythroid response since erythroid cells represent $\sim 95 \%$ of blood cells. We chose a "peripheral stress" through hemolytic anemia (phenylhydrazine administration known to destroy mature red blood cells, RBC) to avoid direct alterations of the stem cell compartments (Hara and Ogawa, 1976; Klinken et al., 1987). So far, most of studies focused their attention on committed progenitors, the effects on more immature compartments being poorly addressed.

Here, we demonstrate that stress and unperturbed hematopoiesis can be combined in a single system based on a 6-compartment modeling. We conducted in silico modelling and in vivo experiments to integrate homeostasis and stress hematopoiesis. We observed that transient hematopoietic stress impacts all primitive HSPC compartments, with a large rebound effect inducing a delay in the hematopoietic system. A steady state model (i.e. with constant parameter 
values) cannot explain the fast return of $\mathrm{RBC}$ to equilibrium and a model whose regulation depends directly on the different compartment sizes cannot explain the observed rebound effect. Then, these effects were taken into account in our in silico model: We integrated timedependent regulations depending indirectly on compartment sizes. Self-renewal and differentiation dynamics were modulated through the dynamics of two regulators ( $u_{r}$ and $u_{d}$ ). The model was finely calibrated using a novel stochastic optimization algorithm (CMA-ES) (Hansen and Ostermeier, 2001) based on the experimental observations .

\section{RESULTS}

We first developed a mathematical model able to recapitulate steady-state hematopoiesis from quiescent LT-HSC to RBC. Modelling quiescence/kinetics of proliferation/differentiation processes requires a theoretical number of compartments between LT-HSC and RBC. However, deciphering an exact compartment number remains elusive since nature and number of compartments are not standardized from one study to another. Using a mathematical modelling, we deduced that the theoretical number of compartments should rely upon at least 3 criteria for each compartment: 1- size, 2- duration of proliferative steps and 3-self-renewal versus differentiation capacities.

We assumed that an accurate model should integrate stochasticity and amplification in each compartment as well as plasticity in the number of intermediate compartments. Then, a stochastic multi-type branching process was designed to recapitulate native (unperturbed) hematopoiesis, leading to derivation of a macroscopic deterministic system. In vivo steady-state 
parameters applied to this model helped us to determine the minimal number of amplification motors ( $\mathrm{k}$ cell compartments) necessary to obtain a lifelong stable RBC production.

\section{Modelling of unperturbed early erythropoiesis}

Our model describes a hierarchy of k cell compartments evolving over time. Each cell of a given compartment divides with a constant rate independently from the others and is characterized by its division rate, its self-renewal and differentiation capacity, and for the last compartment (corresponding to $\mathrm{RBC}$ ), its death rate. The entire dynamics of hematopoiesis presented in Figure $1 A$ and $1 B$ is summarized as follows:

1 - For any $\mathrm{i}=1,, \mathrm{k}-2$, a cell belonging to the $\mathrm{i}$ compartment divides at rate $\tau_{\mathrm{i}}>0$ in two cells of the same compartment with a probability $0<\mathrm{p}_{\mathrm{r}}^{\mathrm{i}}<1$ (self-renewal) or in two cells of compartment

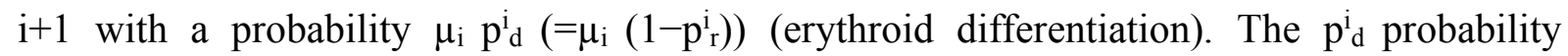
corresponds to differentiation, and $\mu_{\mathrm{i}}$ to commitment towards erythroid rather than nonerythroid lineages. The $\mathrm{i}=1$ compartment corresponds to LT-HSC and $\mathrm{i}=\mathrm{k}$ to mature $\mathrm{RBC}$.

2- A (k-1)-type cell "divides" at rate $\tau_{\mathrm{k}-1}>0$. Upon division, the cell renews with probability

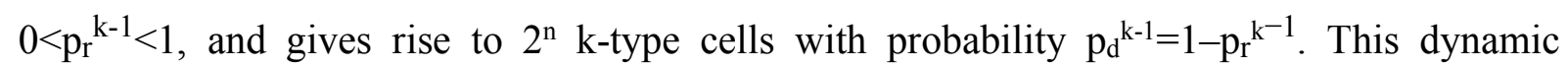
summarizes the $\mathrm{n}$ mitosis with negligible self-renewal observed at the end of erythroid differentiation. This amplification was simplified as $2^{\mathrm{n}} \mathrm{RBC}$ issued from 1 cell of the previous compartment since terminal erythroid differentiation has been largely modeled before and is not our main concern.

3 - A k-type cell corresponding to mature RBC dies at rate $\tau_{\mathrm{k}}>0$. The estimation HSPC death rate is estimated to $2-4 \%$ per day and then was neglected in our modeling (Domen et al., 2000). We were aware that stem cell division could be asymmetric (a cell of type i giving birth to two daughter cells, one of type $i$ and the other of type $i+1)$. However, from our data, it was not 
possible to distinguish symmetrical from asymmetrical divisions. We therefore neglected the latter for parameter identifiability purpose.

Furthermore, presuming that LT-HSC compartment is at equilibrium, the number of selfrenewing LT-HSC is equal to the number of differentiating LT-HSC, i.e $\mathrm{p}^{1} \mathrm{~d}^{=} \mathrm{p}^{1}$. Moreover, for any $i \in\{2, ., k-1\}, p_{d}^{i_{d}}-p_{r}^{i_{r}}>0$ to ensure the stability of the system. For any type $i=2, ., k-1$, the $i-$ compartment differentiation factor is defined as $D_{i}=p_{d}^{i}-p_{r}^{i}$. Since $p_{d}^{i}+p_{r}^{i}=1, D_{i}=1-2 p_{r}^{i}=2 p_{d}^{i}-$ 1.

According to the literature (Ethier and Kurtz, 1986), LT-HSC number was large enough to approximate the stochastic model by a differential equation system (Figure 1 C); therefore compartment sizes at equilibrium can be expressed (Figure 1D). In particular, the i compartment size relies upon the one of compartment $i-1$ multiplied by $1 / \mathrm{D}_{\mathrm{i}}$, meaning that the smaller the $\mathrm{D}_{\mathrm{i}}$, the bigger the i compartment size.

As a first step, we assumed that the $D_{i}$ are equal to a positive $D$ value and the $\mu_{i}$ probabilities equal to 1 . Then a direct relationship can be computed between the LT-HSC number, their division rate, the $\mathrm{D}$ parameter, the $\mathrm{n}$ number of final mitoses, the $\mathrm{RBC}$ number, and their death rate (Figure $\mathbf{1 E}$ ). The minimal number of amplification motors / compartments was computed based on this formula. Such method was drafted in Dingly et al. 2007 (Dingli et al., 2007) with a simple model which does not include temporal dynamics.

\section{Determination of the minimal compartment number}

The determination of the theoretical minimum number of compartments was based on Figure 1E. The RBC number and their death rate are known (ie $\approx 10^{10}$ cells/mouse, and 40 -day life expectancy). LT-HSC number was evaluated from the proportion of LT-HSC (Lin- Sca- $1^{+}$ckit+, LSK CD150 ${ }^{+}$CD48- ) estimated as described in Figure S1. Knowing that a C57B16 mouse displays $\approx 250 \times 10^{6}$ BM cells (Boggs, 1984; Chervenick et al., 1968; Mahajan et al., 2015), the 
LT-HSC number was around 15248 +/- 2200/mouse. The LT-HSC division rate was computed from the proportion of LT-HSC retaining their phenotype after 20 hours of BrdU incorporation at steady state (1.82 in [0-4,7] \% of cycling LT-HSC) (Figure $\mathbf{1 F}$ and Figure S1). Hence LTHSC division rate was approximated by $1 / 100$ per day. Assuming that $D_{i}$ must increase as a function of $i$ and since $D_{k}=1$ (no self-renewal), $D_{i}$ belongs to $\left[D_{2} ; 1\right]$. As in Busch's report (Busch et al., 2015), the second compartment corresponds to the ST-HSC compartment. Then minimal value for $\mathrm{D}_{2}\left(\mathrm{D}_{2} \geq 0.16\right)$ was computed (Figure $\left.1 D\right)$ with bounds for division rate (Figure $\mathbf{1 F}$ and Table 1).

The $\mathrm{n}$ number of mitosis between the two last compartments was assessed as follows: we assume that the k-1 compartment is upstream of BFU-E (Burst-Forming-Unit Erythroid)enriched cells known to perform 11 cell divisions to in vitro generate mature $\mathrm{RBC}$ (Li et al., 2019). Therefore " $n$ " should be over 12.

Taking into consideration all these parameters (Figure $1 \boldsymbol{E}$ ), we computed that if $\mathrm{k}=5$, then $\mathrm{D}=0.12$; if $\mathrm{k}=6$, then $\mathrm{D}=0.23$; if $\mathrm{k}=7$, then $\mathrm{D}=0.35$. Therefore, the minimum compartment number to obtain $\mathrm{D} \in[0.16 ; 1]$ was 6 . As previously assessed, the last steps (MEP to RBC) was simplified as $2^{\mathrm{n}}$ RBC from 1 MEP. We focused our attention on HSPC compartments and roughly summarized behavior of committed erythroid progenitors. To match these 6 compartments to cytometric analysis of hematopoiesis, we then in vivo evaluated the cell number and division rates of LT-HSC, ST-HSC, MPP, CMP, MEP, and MEP to RBC compartments (Table 2).

\section{Parameter calibration of the mathematical model for steady-state erythropoiesis.}

We first gave bounds to the division rate per day. By considering variations due to BrdU experimental procedure, we used bounds rather than median values to delineate division rates 
(Figure $1 F$ ). Bounds offered the opportunity to include standard deviation from one experiment to another and variability of the time interval between BrdU injection and analysis (20h+/-4h).

We then computed appropriate values of all parameters (Table 2). We took into consideration 1- population size (Table 1), 2- $\mu_{\mathrm{i}}$ probabilities of differentiation toward the erythroid lineage (based on Busch's data), 3- decreased probability of self-renewal along the differentiation process, and 4- bounds of the division rate of each cell type. The $\mu_{\mathrm{i}}$ erythro-myeloid commitment probabilities were obtained considering Busch et al. data (Busch et al., 2015) and dividing the differentiation rate toward erythro-myeloid lineages by the sum of differentiation rates toward all lineages. Based on decreasing probability of self-renewal in the different compartments along the differentiation process, $\mathrm{D}_{\mathrm{i}}$ were computed allowing calibration of the model (Figure 1D). Our results (Table 2) showed that this steady state erythropoiesis model was able to reproduce unperturbed native hematopoiesis for at least two years, the normal mouse lifetime.

\section{Steady-state model applied to acute erythroid stress.}

In order to validate the 6-amplification compartment model in stress hematopoiesis, we induce an acute hemolytic anemia using phenylhydrazine (PHZ) administration (Figure S2A). After a $40 \%$-hemolysis stress observed at day 3, a rapid recovery of RBC was evidenced after 10-16 days (Figure 2A). Our 6-step model was applied to recapitulate $\mathrm{RBC}$ recovery but the recovery time exceeded one month, in total discrepancy with observed biological data (Figure $2 \boldsymbol{A}$ ). This indicated that, although able to fulfill steady state hematopoiesis, this model was unable to recapitulate the hematopoietic stress response just like previously observed by Busch et al. using their own model (Busch et al., 2015). We then considered that our model requires additional regulations during stress hematopoiesis. 


\section{Analysis of compartment kinetics during acute hematopoietic stress.}

In order to decrypt biological mechanisms responsible for this fast $\mathrm{RBC}$ recovery, we analyzed all compartment modifications after PHZ injection in blood, BM, and spleen. Briefly, during the first 3 days after injection, we observed a drastic RBC fall, and an increase in platelets and leukocytes counts (Figure $\mathbf{2} \boldsymbol{A}-\boldsymbol{C}$ ). While total number of BM cells was slightly reduced at day $3(-25 \%)$ and enhanced at day $10(+33 \%)$ (Figure $2 G)$, spleen weight strongly increased $24 \mathrm{~h}$ after PHZ injection (Figure $\mathbf{2 D - F}$ ), becoming 3 times larger than normal at day 3 , as previously observed after erythroid (Hara and Ogawa, 1976; Sanchez et al., 2006) and social stress in mice (McKim et al., 2018). The three hematopoietic tissues were analyzed to assess proportion and absolute cell numbers in the different compartments (LT-HSC, ST-HSC, MPP, CMP, and MEP) as well as their percentages into cell cycle (BrdU incorporation), and apoptosis (AnnexinV labelling) during the hemolytic phase. In BM, a decrease in the size of all compartments (from LT-HSC to CMP) was evidenced. BM MEP population remained relatively stable during this phase, while a huge increase in the number of splenic MEP was observed 3 and 5 days after PHZ injection (Figure 2G). No difference in BrdU incorporation was noticed at day 3 in the different BM compartments except for MEP, which displayed a 2fold increased cell proliferation, as compared to D0 (Figure S2F). To further get insight into mechanisms involved in the drastic decrease of compartment size, we analyzed apoptosis. No increase in the proportion of AnnexinV-labelled cells was observed whatever the progenitor compartment examined, allowing us to exclude any excess of cell death in the BM progenitor compartments (Figure S3B). Blood cell analysis performed at day 1 and 3 after PHZ injection showed a 15-fold increase in the number of mononuclear cells (Figure $2 \boldsymbol{B}$ ) yet with a negligible proportion of Lin- cells, precluding an egress of LSK from BM to blood (Figure S3A). In spleen, a stress erythropoietic organ in mouse, the number of mature cells increased (3-fold) (Figure $2 \boldsymbol{E}$ ) whereas LSK and CMP compartments displayed no significant variations in cell 
number, ruling out any role of splenic immature progenitors at day 3 (Figure 2G). Lastly, to confirm stemness properties of LT-HSC assessed by cytometry, competitive BM transplantation with $50 \%$ of CD45.1 BM cells from untreated animals and 50\% of total BM cells from day 3-PHZ-treated mice were performed in CD45.2 9.5 Gy-irradiated recipients. Blood chimerism analysis 3 months post-transplantation showed a decreased proportion of PHZ-treated cells, confirming the decrease number of LT-HSC in BM of day3-PHZ-treated mice (Figure S3C).

The decrease of BM progenitor compartment sizes, without increased proliferation or apoptosis or egress to the spleen or the blood, together with a stable number of MEP displaying a twofold increased proliferation in BM and spleen, was the result of a rapid differentiation process, like a flush, to quickly compensate loss of RBC through a versatile mechanism.

\section{Recovery of progenitor compartment after PHZ stress.}

To assess dynamics of progenitor compartments during recovery after PHZ treatment, we analyzed at days $3,5,7,10,16$ and 28 the different compartment sizes and proliferation rates. Recovery was almost effective in all compartments at day 7-10 (Figure 4A). Surprisingly, at day 10, all compartments displayed a 2-3-fold increased cell numbers before returning to normal values at day 28. In parallel, BrdU analysis showed that all BM compartments exhibited a drastic increased cell proliferation at day-10 (the time point of the hematocrit normalization). Thereafter, BrdU incorporation returned to normal values at days 16 and 28 (Figure S2C-G).

\section{Modelling steady-state and stress hematopoiesis by adding compartment regulations}

The steady state model previously introduced could not recapitulate the fast return of RBC to equilibrium. Therefore, to model all at once unperturbed and stress hematopoiesis, we 
introduced regulations by assuming that previously defined parameters depend indirectly upon compartment size through dynamics of two regulators ( $u_{r}$ and $\left.u_{d}\right)$ modulating self-renewal and differentiation, bringing positive and negative effects on compartment sizes, respectively (Figure 3A).

Dynamics of the two regulators followed a double system of production and clearance. The production is given by Michaelis-Menten type functions depending on BM cell numbers. The clearance of the regulator after its production is given by a linear degradation term (Figure $3 \boldsymbol{B}$ ). This modelling induced a delay between dynamics of the regulators and changes in compartment sizes, explaining the huge oscillations in cell numbers after PHZ injection.

Assuming that the proliferation rate during late erythropoiesis is regulated in a specific manner (Erythropoietin, Stem Cell Factor, etc...), RBC production dynamics from MEP is controlled with a third type of regulation. MEP differentiation gives birth to $2^{\mathrm{n}(\mathrm{t})} \mathrm{RBC}$ summarizing the $\mathrm{n}(\mathrm{t})$ last mitosis with a Hill function (Michaelis-Menten's type) of the RBC number (Figure 3C). In addition, we hypothesized that differentiation towards a non-erythroid lineage was not affected by all these regulators. Parameters of the regulated-model were calibrated using a stochastic optimization algorithm based on a CMA-ES method (Covariance Matrix Adaptation in Evolution Strategy), which minimizes discrepancy between in silico simulated and experimental data (see Suppl. data). Optimal parameters obtained by this method are presented in Table 3 and the corresponding cell dynamics in Figure $\mathbf{4 B}$. The later matched with the experimental data in all compartments in stress condition (the oscillation effect) as well as in steady state (second part of the trajectory). Moreover, division rate values were deduced as function of time for each cell type (Table 4). 


\section{DISCUSSION}

Our present work provides a mathematical model able to reconcile steady state and stress hematopoiesis. Furthermore, it highlights a mechanism by which transient stress exposure leads to a protracted influence on all progenitor compartments including LT-HSC, leading to a fast repopulation of mature compartment.

To decipher mechanisms involved in the normalization of RBC number at steady state and after an acute stress, we first developed a compartmental model of hematopoiesis. The theoretical number of compartments sufficient to fulfill stable erythropoiesis was relied upon the number of LT-HSC and mature RBC. Our modelling proposes that 6-amplification compartments are sufficient to ensure steady state erythropoiesis. We hypothesized that the last compartment was resumed from MEP to RBC as a simple amplification factor according to the $\mathrm{n}$ number of mitosis required from $1 \mathrm{MEP}$ to RBC. Based on the division number between BFU-E and erythrocytes, this n number could vary from 11 to 14 (Li et al., 2019). We neglected megakaryocytic differentiation that theoretically only corresponds to $20 \%$ of the MEP differentiation (Mori et al., 2015) and other myelo-lymphoid cells representing quantitative minorities. Then, this 6-compartment model parallels the generally assessed compartment hierarchy with LT-HSC, ST-HSC, MPP, CMP, MEP and RBC.

Our "stress model" was initially the destruction of RBCs by chemical hemolysis. Nevertheless, this process also induced a huge inflammatory response leading to changes in all blood cell types and a huge cytokine storm in the next few days after hemolysis (data not shown), confirming that stress hematopoiesis relied on regulatory mechanisms different from those of unperturbed hematopoiesis, as previously illustrated by the megakaryocytic and the granulocytic differentiation processes (Haas et al., 2015; Kang et al., 2020). Based on our data and modelling, we demonstrate here that ( $u_{r}$ and $\left.u_{d}\right)$ regulations of compartment proliferation 
and differentiation are required to reproduce stress response while dispensable for steady-state erythropoiesis, these regulators remaining constant in the latter.

Previous mathematical models based on in vivo experiments mostly described hematopoiesis dynamics at steady state. These studies rely upon parameters such as cell division rates or probabilities of self-renewing (Abkowitz et al., 2000; Busch et al., 2015; Foudi et al., 2009; Klose et al., 2019; MacKey, 2001; Manesso et al., 2013; Sawai et al., 2016). Models integrating steady state as well as in vivo stress hematopoiesis rarely reproduce oscillations observed in the size of the progenitor compartments apart from the modelling (Angulo et al., 2018; Crauste et al., 2008, 2010; Klose et al., 2019; Loeffler et al., 1989; Manesso et al., 2013; MarciniakCzochra et al., 2009; Roeder et al., 2005). These reports modelized the regulation dynamics by a differential equation with a delay, enabling to predict the oscillating behavior of progenitor compartments characterized by a regulated self-renewal. However they integrated only a theoretical 3-compartment model (stem cells/progenitors/mature erythrocytes) based on RBC recovery data after stress. Other regulation-based models have been developed but did not integrated in vivo data (Kirouac et al., 2010; Mahadik et al., 2019).

In contrast, our present 6-compartment model was designed to reproduce the in vivo dynamics observed throughout unperturbed and stress erythropoiesis, using 8 differential equations, including two for regulator dynamics and naturally created a delay in the oscillation phenomenon due to the duration needed for regulator production and clearance and then better match with hematopoiesis process.

Little is known regarding in vivo consequences of a "peripheral" stress on upstream progenitor compartments such as LT-, ST-HSC, MPP, CMP, and MEP. Our experiments demonstrated that after an acute stress destroying RBC, the first compensatory mechanism entails all compartments, from LT-HSC to CMP, and surprisingly, induces as a first step, differentiation 
without proliferation just like a flush. Thereafter, all depleted compartments enter into proliferation during a recovery phase, the division rate of each progenitor compartment reaching its maximum value around day 11 but still remained lower than 3 divisions per day (in accordance with biological data) (Table 4). This recovery phase not only replenishes the different "flushed" compartments but exceeds steady-state values. Normalization of all compartment sizes occurs in a third phase just like spring oscillation around the standard values.

These oscillations in cell number from each compartment are in accordance with in vivo data previously reported in post-chemotherapy stressed hematopoiesis (Busch et al., 2015). In contrast, the MEP compartment was not subjected to such a high regulation process in the bone marrow probably because of the well-known spleen stress erythropoiesis process that follows a different kind of regulation as reported here and in previous reports (Perry et al., 2009).

In conclusion, we modeled the plasticity of hematopoiesis recapitulating steady-state as well as stress hematopoiesis, no compartment being "protected" from stress consequences. Our mathematical model suggests that regulators of hematopoiesis are dispensable during steadystate hematopoiesis. Thus, our model opens the way to better understand malignant clonal development and invasion: Stem cell disorders just like leukemias and more generally cancers could arise from successive stress if pathological clonal cells react differently from normal cells in response to aggression.

\section{References}

Abkowitz, J.L., Golinelli, D., Harrison, D.E., and Guttorp, P. (2000). In vivo kinetics of murine hemopoietic stem cells. Blood 96, 3399-3405.

Angulo, O., Gandrillon, O., and Crauste, F. (2018). Investigating the role of the experimental protocol in phenylhydrazine-induced anemia on mice recovery. J Theor Biol 437, 286-298. 
Boggs, D.R. (1984). The total marrow mass of the mouse: a simplified method of measurement. Am. J. Hematol. 16, 277-286.

Busch, K., and Rodewald, H.-R. (2016). Unperturbed vs. post-transplantation hematopoiesis: both in vivo but different. Curr Opin Hematol 23, 295-303.

Busch, K., Klapproth, K., Barile, M., Flossdorf, M., Holland-Letz, T., Schlenner, S.M., Reth, M., Höfer, T., and Rodewald, H.-R. (2015). Fundamental properties of unperturbed haematopoiesis from stem cells in vivo. Nature 518, 542-546.

Carrelha, J., Meng, Y., Kettyle, L.M., Luis, T.C., Norfo, R., Alcolea, V., Boukarabila, H., Grasso, F., Gambardella, A., Grover, A., et al. (2018). Hierarchically related lineage-restricted fates of multipotent haematopoietic stem cells. Nature 554, 106-111.

Chapple, R.H., Tseng, Y.-J., Hu, T., Kitano, A., Takeichi, M., Hoegenauer, K.A., and Nakada, D. (2018). Lineage tracing of murine adult hematopoietic stem cells reveals active contribution to steady-state hematopoiesis. Blood Adv 2, 1220-1228.

Chervenick, P.A., Boggs, D.R., Marsh, J.C., Cartwright, G.E., and Wintrobe, M.M. (1968). Quantitative studies of blood and bone marrow neutrophils in normal mice. Am. J. Physiol. $215,353-360$.

Crauste, F., Pujo-Menjouet, L., Génieys, S., Molina, C., and Gandrillon, O. (2008). Adding self-renewal in committed erythroid progenitors improves the biological relevance of a mathematical model of erythropoiesis. J Theor Biol 250, 322-338.

Crauste, F., Demin, I., Gandrillon, O., and Volpert, V. (2010). Mathematical study of feedback control roles and relevance in stress erythropoiesis. J Theor Biol 263, 303-316.

Dingli, D., Traulsen, A., and Pacheco, J.M. (2007). Compartmental architecture and dynamics of hematopoiesis. PLoS One 2, e345.

Domen, J., Cheshier, S.H., and Weissman, I.L. (2000). The role of apoptosis in the regulation of hematopoietic stem cells: Overexpression of Bcl-2 increases both their number and repopulation potential. J Exp Med 191, 253-264.

Eich, M., Trumpp, A., and Schmitt, S. (2019). OMIP-059: Identification of Mouse Hematopoietic Stem and Progenitor Cells with Simultaneous Detection of CD45.1/2 and Controllable Green Fluorescent Protein Expression by a Single Staining Panel. Cytometry A 95, 1049-1052.

Ethier, S., and Kurtz, T. (1986). Markov Processes: Characterization and Convergence. In Markov Processes: Characterization and Convergence, (John Wiley \& Sons, Inc.), p.

Foudi, A., Hochedlinger, K., Van Buren, D., Schindler, J.W., Jaenisch, R., Carey, V., and Hock, H. (2009). Defining hematopoietic stem and progenitor cell turnover by analysis of histone 2BGFP dilution. Nature Biotechnology 27, 84.

Giladi, A., Paul, F., Herzog, Y., Lubling, Y., Weiner, A., Yofe, I., Jaitin, D., CabezasWallscheid, N., Dress, R., Ginhoux, F., et al. (2018). Single-cell characterization of haematopoietic progenitors and their trajectories in homeostasis and perturbed haematopoiesis. Nat Cell Biol 20, 836-846. 
Haas, S., Hansson, J., Klimmeck, D., Loeffler, D., Velten, L., Uckelmann, H., Wurzer, S., Prendergast, Á.M., Schnell, A., Hexel, K., et al. (2015). Inflammation-Induced Emergency Megakaryopoiesis Driven by Hematopoietic Stem Cell-like Megakaryocyte Progenitors. Cell Stem Cell 17, 422-434.

Hansen, N., and Ostermeier, A. (2001). Completely derandomized self-adaptation in evolution strategies. Evolutionary Computation 9, 159-195.

Hara, H., and Ogawa, M. (1976). Erthropoietic precursors in mice with phenylhydrazineinduced anemia. Am J Hematol 1, 453-458.

Kang, Y.-A., Pietras, E.M., and Passegué, E. (2020). Deregulated Notch and Wnt signaling activates early-stage myeloid regeneration pathways in leukemia. J. Exp. Med. 217.

Kirouac, D.C., Ito, C., Csaszar, E., Roch, A., Yu, M., Sykes, E.A., Bader, G.D., and Zandstra, P.W. (2010). Dynamic interaction networks in a hierarchically organized tissue. Mol Syst Biol $6,417$.

Klinken, S.P., Holmes, K.L., Fredrickson, T.N., Erner, S.M., and Morse, H.C. (1987). Phenylhydrazine stimulates lymphopoiesis and accelerates Abelson murine leukemia virusinduced pre-B cell lymphomas. J Immunol 139, 3091-3098.

Klose, M., Florian, M.C., Gerbaulet, A., Geiger, H., and Glauche, I. (2019). Hematopoietic Stem Cell Dynamics Are Regulated by Progenitor Demand: Lessons from a Quantitative Modeling Approach. Stem Cells 37, 948-957.

Laurenti, E., and Göttgens, B. (2018). From haematopoietic stem cells to complex differentiation landscapes. Nature 553, 418-426.

Li, H., Natarajan, A., Ezike, J., Barrasa, M.I., Le, Y., Feder, Z.A., Yang, H., Ma, C., Markoulaki, S., and Lodish, H.F. (2019). Rate of Progression through a Continuum of TransitAmplifying Progenitor Cell States Regulates Blood Cell Production. Dev Cell 49, 118-129.e7.

Liggett, L.A., and Sankaran, V.G. (2020). Unraveling Hematopoiesis through the Lens of Genomics. Cell 182, 1384-1400.

Loeffler, M., Pantel, K., Wulff, H., and Wichmann, H.E. (1989). A mathematical model of erythropoiesis in mice and rats. Part 1: Structure of the model. Cell Tissue Kinet 22, 13-30.

MacKey, M.C. (2001). Cell kinetic status of haematopoietic stem cells. Cell Prolif 34, 71-83.

Mahadik, B., Hannon, B., and Harley, B.A.C. (2019). A computational model of feedbackmediated hematopoietic stem cell differentiation in vitro. PLoS One 14, e0212502.

Mahajan, M.M., Cheng, B., Beyer, A.I., Mulvaney, U.S., Wilkinson, M.B., Fomin, M.E., and Muench, M.O. (2015). A quantitative assessment of the content of hematopoietic stem cells in mouse and human endosteal-bone marrow: a simple and rapid method for the isolation of mouse central bone marrow. BMC Hematol 15, 9.

Manesso, E., Teles, J., Bryder, D., and Peterson, C. (2013). Dynamical modelling of haematopoiesis: an integrated view over the system in homeostasis and under perturbation. J R Soc Interface 10, 20120817. 
Marciniak-Czochra, A., Stiehl, T., Ho, A.D., Jäger, W., and Wagner, W. (2009). Modeling of asymmetric cell division in hematopoietic stem cells--regulation of self-renewal is essential for efficient repopulation. Stem Cells Dev 18, 377-385.

McKim, D.B., Yin, W., Wang, Y., Cole, S.W., Godbout, J.P., and Sheridan, J.F. (2018). Social Stress Mobilizes Hematopoietic Stem Cells to Establish Persistent Splenic Myelopoiesis. Cell Rep 25, 2552-2562.e3.

Mori, Y., Chen, J.Y., Pluvinage, J.V., Seita, J., and Weissman, I.L. (2015). Prospective isolation of human erythroid lineage-committed progenitors. Proc Natl Acad Sci U S A 112, 9638-9643.

Notta, F., Zandi, S., Takayama, N., Dobson, S., Gan, O.I., Wilson, G., Kaufmann, K.B., McLeod, J., Laurenti, E., Dunant, C.F., et al. (2016). Distinct routes of lineage development reshape the human blood hierarchy across ontogeny. Science 351, aab2116.

Orkin, S.H., and Zon, L.I. (2008). Hematopoiesis: an evolving paradigm for stem cell biology. Cell 132, 631-644.

Paul, F., Arkin, Y., Giladi, A., Jaitin, D.A., Kenigsberg, E., Keren-Shaul, H., Winter, D., LaraAstiaso, D., Gury, M., Weiner, A., et al. (2015). Transcriptional Heterogeneity and Lineage Commitment in Myeloid Progenitors. Cell 163, 1663-1677.

Pei, W., Feyerabend, T.B., Rössler, J., Wang, X., Postrach, D., Busch, K., Rode, I., Klapproth, K., Dietlein, N., Quedenau, C., et al. (2017). Polylox barcoding reveals haematopoietic stem cell fates realized in vivo. Nature $548,456-460$.

Pei, W., Shang, F., Wang, X., Fanti, A.-K., Greco, A., Busch, K., Klapproth, K., Zhang, Q., Quedenau, C., Sauer, S., et al. (2020). Resolving Fates and Single-Cell Transcriptomes of Hematopoietic Stem Cell Clones by PolyloxExpress Barcoding. Cell Stem Cell 27, 383-395.e8.

Perry, J.M., Harandi, O.F., Porayette, P., Hegde, S., Kannan, A.K., and Paulson, R.F. (2009). Maintenance of the BMP4-dependent stress erythropoiesis pathway in the murine spleen requires hedgehog signaling. Blood 113, 911-918.

Rodriguez-Fraticelli, A.E., Wolock, S.L., Weinreb, C.S., Panero, R., Patel, S.H., Jankovic, M., Sun, J., Calogero, R.A., Klein, A.M., and Camargo, F.D. (2018). Clonal analysis of lineage fate in native haematopoiesis. Nature 553, 212-216.

Roeder, I., Kamminga, L.M., Braesel, K., Dontje, B., de Haan, G., and Loeffler, M. (2005). Competitive clonal hematopoiesis in mouse chimeras explained by a stochastic model of stem cell organization. Blood 105, 609-616.

Sanchez, M., Weissman, I.L., Pallavicini, M., Valeri, M., Guglielmelli, P., Vannucchi, A.M., Migliaccio, G., and Migliaccio, A.R. (2006). Differential amplification of murine bipotent megakaryocytic/erythroid progenitor and precursor cells during recovery from acute and chronic erythroid stress. Stem Cells 24, 337-348.

Sawai, C.M., Babovic, S., Upadhaya, S., Knapp, D.J.H.F., Lavin, Y., Lau, C.M., Goloborodko, A., Feng, J., Fujisaki, J., Ding, L., et al. (2016). Hematopoietic Stem Cells Are the Major Source of Multilineage Hematopoiesis in Adult Animals. Immunity 45, 597-609. 
Säwen, P., Eldeeb, M., Erlandsson, E., Kristiansen, T.A., Laterza, C., Kokaia, Z., Karlsson, G., Yuan, J., Soneji, S., Mandal, P.K., et al. (2018). Murine HSCs contribute actively to native hematopoiesis but with reduced differentiation capacity upon aging. Elife 7.

Schoedel, K.B., Morcos, M.N.F., Zerjatke, T., Roeder, I., Grinenko, T., Voehringer, D., Göthert, J.R., Waskow, C., Roers, A., and Gerbaulet, A. (2016). The bulk of the hematopoietic stem cell population is dispensable for murine steady-state and stress hematopoiesis. Blood 128, 2285-2296.

Sun, J., Ramos, A., Chapman, B., Johnnidis, J.B., Le, L., Ho, Y.-J., Klein, A., Hofmann, O., and Camargo, F.D. (2014). Clonal dynamics of native haematopoiesis. Nature 514, 322-327.

Till, J.E., and McCulloch, E.A. (2012). A direct measurement of the radiation sensitivity of normal mouse bone marrow cells. 1961. Radiat Res 178, AV3-7.

Velten, L., Haas, S.F., Raffel, S., Blaszkiewicz, S., Islam, S., Hennig, B.P., Hirche, C., Lutz, C., Buss, E.C., Nowak, D., et al. (2017). Human haematopoietic stem cell lineage commitment is a continuous process. Nat Cell Biol 19, 271-281. 


\section{MATERIALS AND METHODS}

\section{Animals}

We used adult 6-12 weeks old C57BL/6 Ly5.2 and Ly5.1 mice obtained from Janvier (Le Genest, France). Mice were bred and maintained in pathogen-free conditions in our Institute Animal facilities Unit for Laboratory Animal Medicine at the Université de Paris. All procedures performed were approved by local Committee on the Use and Care of Animals and by the Institutional Animal Care and Use Committee.

\section{Hematologic evaluations}

Orbital plexus blood was collected in EDTA tubes from anesthetized mice. Blood cell counts were determined using automated blood coulter (MS9, Schloessing Melet, Cergy-Pontoise, France). Blood samples were used for cytometry analysis. Serum were collected, stored at $20^{\circ} \mathrm{C}$ before assessing cytokine levels.

\section{BM and spleen Analysis}

Mice were killed by cervical dislocation. Bones (femurs, tibias, pelvis and humerus) and spleen were harvested, muscle and tendon tissue were removed using a scalpel and kimwipes. BM and spleens were used for cell count, and cytometry.

$\mathrm{BM}$ fraction was flushed out using a syringe containing 1xPBS complemented with $2 \%$ Fetal Bovine Serum (FBS). The resulting cell suspension were filtered through a $40 \mu \mathrm{M}$ cell strainer (Corning, NY, USA) and pelleted by centrifugation.

For mechanical grinding, spleens were smashed and ground between rough sides of frosted glass slides, and cells were collected in DMEM containing 2\%FBS. After incubation in a 24well plate for $30 \mathrm{~min}$ at $37^{\circ} \mathrm{C}$ in a humidified incubator, cell suspensions were passed through a $40 \mu \mathrm{m}$ cell strainer, and cells were re-suspended in DMEM containing 10\%FBS. Suspensions were subjected to cytometry analysis after RBC lysis. 


\section{Cytometry analysis}

Erythrocytes were lysed using ACK Lysing Buffer (Lonza, Basel, Switzerland) before flow cytometry stainings. Total BM and spleen cells were stained with Zombie Viability kit for $15 \mathrm{~min}$ at room temperature, and thereafter stained with biotinylated anti-mouse Lineage Cocktail antibodies for 30 min (Biolegend). After washing, cells were stained for 30 min using the following monoclonal antibodies in the BD Horizon Brilliant staining buffer: anti-CD117/cKit (2B8)-BB700 and anti-CD34 (RAM34)-AF647 (BD Pharmingen); anti-Ly6a/Sca-1 (D7)BV510; anti-CD150 (TC15-12F12.2)-PE-Cy7; anti-CD48 (HM48-1)-BV711; Streptavidin APC-Cy7 (Biolegend).

For proliferation analysis, surface stainings were performed as described above, and cells were proceeded for cell proliferation according to manufacturer's recommendations (BD Pharmingen BrdU Flow kits) with BrdU-AF488 (BD Biosciences, Franklin Lakes, NJ, USA). Data acquisition and/or data analysis were performed on the Cochin Cytometry and Immunobiology Facility Cytometry analyses on a Fortessa cytometer (Becton Dickinson), and analyses were done on Kaluza software.

To assess cell viability, surface labelled cells were resuspended in AnnexinV binding buffer, and AnnexinV (FITC) was added 15min before analysis (FITC-conjugated AnnexinV labeling detection kit, BD Pharmingen).

\section{Reconstitution assays}

Donor cells were isolated from 6-12-week-old B6.SJL-Ptprc ${ }^{\mathrm{a} P e p c} \mathrm{c}^{\mathrm{b}} / \mathrm{BoyCrl}$ Congenic mice (Ly5.1) and Ly5.2 mice after Phenylhydrazine (PHZ) (60 mg/Kg, IP) injection or not. From these mice, hind limbs were extracted and cleaned. Total BM were flushed, then passed through a $70 \mu \mathrm{M}$ cell strainer to obtain a single cell suspension. A mix of cells from PHZ-treated mouse and untreated mouse was prepared in a 1:1 ratio. A mix of $5 \times 10^{6}$ cells were resuspended in a 
total volume of $0.2 \mathrm{~mL}$ and transplanted into 5 irradiated (9Gy) CD45.1 C57/BL6 recipient mice. Chimerism analysis was performed three months post-reconstitution using cytometry.

\section{Statistical analysis}

Results are presented as mean+/-SD. Data were analyzed through 2-tailed Student t-test.

\section{ACKNOWLEDGMENTS}

The authors are grateful to C. Chomienne for helpful discussions and improving the English manuscript. The authors greatly acknowledge the Cochin Cytometry and Immunobiology Facility and the IRSL Animal Facility, Université de Paris.

\section{AUTHORSHIP}

$\mathrm{CB}, \mathrm{SiG}, \mathrm{VB}, \mathrm{SM}$ conducted modeling of the paper, PG, CL, KB, MHS, EL and StG conducted in vivo experimental procedures, EL and SG performed the analysis of the data. $\mathrm{CB}, \mathrm{SiG}, \mathrm{EL}$, SM and StG wrote the paper.

DISCLOSURE OF CONFLICT INTEREST. The authors declare no competing financial interests. 


\section{TABLES}

\begin{tabular}{|l|c|c|}
\hline \multicolumn{1}{|c|}{ Cell Type } & $\mathbf{n}\left(\mathbf{1 0}^{\mathbf{6}} / \mathbf{m o u s e}\right)$ & $\boldsymbol{B r d U}(\%)$ \\
\hline LT-HSC & $0.011+/-0.070$ & $2.35+/-2.71$ \\
\hline$S T-H S C$ & $0.022+/-0.013$ & $0.90+/-0.75$ \\
\hline$M P P$ & $0.066+/-0.045$ & $6.32+/-3.58$ \\
\hline$C M P$ & $0.196+/-0.111$ & $12.42+/-2.31$ \\
\hline$M E P$ & $0.358+/-0.189$ & $31.75+/-1.15$ \\
\hline$G M P$ & $0.677+/-0.430$ & $19.50+/-7.50$ \\
\hline
\end{tabular}

Table 1: Determination of the cell number of each compartment per mouse and the \% of

BrdU positive cells in steady state hematopoiesis. Each value is the mean of at least 6 mice.

\begin{tabular}{|l|l|l|l|l|l|l|}
\hline Compartment & 1 LT-HSC & 2 ST-HSC & 3 MPP & 4 CMP & 5 MEP & 6 RBC \\
\hline Division rate/ day & $\tau_{1}{ }^{*}=0.01$ & $\tau_{2}{ }^{*}=0.03$ & $\tau_{3}{ }^{*}=0.07$ & $\tau_{4}{ }^{*}=0.16$ & $\tau_{5}{ }^{*}=0.35$ & $\tau 6^{*}=1 / 40$ \\
\hline Cell number $\left(10^{3} /\right.$ mouse) & $x_{1}{ }^{*}=11$ & $x_{2}{ }^{*}=22.5$ & $x_{3}{ }^{*}=67$ & $x_{4}{ }^{*}=196$ & $x_{5}{ }^{*}=359$ & $x_{6}{ }^{*}=5.1710^{7}$ \\
\hline D (Differentiation factor) & $\mathrm{D}_{1}=0$ & $\mathrm{D}_{2}=0.16$ & $\mathrm{D}_{3}=0.167$ & $\mathrm{D}_{4}=0.174$ & $\mathrm{D}_{5}=0.176$ & \\
\hline
\end{tabular}

Table 2: Determination of the division rate/day, the size, and the Differentiation factor for each compartment at steady state. 


\begin{tabular}{|l|l|l|l|l|l|}
\hline Proliferation rate & $r_{1}=9.2$ & $r_{2}=6.4$ & $r_{3}=6.4$ & $r_{4}=2.8$ & $r_{5}=0.33$ \\
\hline Erythroid Differentiation rate & $d_{1}=10$ & $d_{2}=8.4$ & $d_{3}=7.7$ & $d_{4}=7.4$ & $d_{5}=4.3$ \\
\hline Regulator clearance (/day) & $m_{1}=0.03$ & $m_{2}=0.2$ & & & \\
\hline $\begin{array}{l}\text { Constants of the regulators production } \\
\text { functions }\end{array}$ & $\mathrm{a}=10^{4}$ & $\mathrm{~b}=100$ & & & \\
\hline Last mitosis number & $\mathrm{c}_{1}=1.18$ & $\mathrm{c}_{2}=31.3$ & & & \\
\hline Steady state value of regulator $u_{1}$ & $u^{*}{ }_{1}=1 /\left(\mathrm{m}_{1}(\mathrm{a}+5)\right)$ & & & & \\
\hline Steady state value of regulator $u_{2}$ & $u^{*}{ }_{2}=5 /\left(\mathrm{m}_{2}(\mathrm{~b}+5)\right)$ & & & & \\
\hline
\end{tabular}

Table 3: Constants of proliferation and erythroid differentiation rate of compartments ; regulator parameter values and mitosis number from MEP to mature RBC after stress.

\begin{tabular}{|l|c|c|c|c|c|}
\hline Cell type division rate value (/day) & LT-HSC & ST-HSC & MPP & CMP & MEP \\
\hline Day 0 & $\tau_{1}{ }^{*}=0.01$ & $\tau_{2}{ }^{*}=0.03$ & $\tau_{3}{ }^{*}=0.07$ & $\tau_{4}{ }^{*}=0.16$ & $\tau_{5}{ }^{*}=0.35$ \\
\hline Day 5 & 0.37 & 0.24 & 0.57 & 0.28 & 0.21 \\
\hline Day 11 & 0.97 & 1.4 & 2.4 & 2.7 & 2 \\
\hline Day 16 & 0.12 & 0.14 & 0.34 & 0.33 & 0.48 \\
\hline
\end{tabular}

Table 4: Division rates at different time points in the different compartments after PHZ administration.

FIGURE LEGENDS

Figure 1: Mathematical parameters required to model steady state Erythropoiesis. $(A)$ Scheme of the cell dynamics of $\mathrm{i}=1$ to $\mathrm{k}-2$ cell type. $C_{i}$ : cell of $i$-type. $\tau_{i}$ : division rate of $i$ type cells. $(B)$ Scheme of the cell dynamics of the two last compartments. $\tau_{k-1}$ : division rate of (k-1)-type cells. $\tau_{k}$ : death rate of RBC (k-type cells). (C) Differential system modeling steadystate erythropoiesis. $\tau_{i}$ : division rate of $i$-type cells. $\tau_{k}$ : death rate of $R B C d x_{i} / d t(t)$ : derivative 
of the $x_{i}$ function at time. $2^{n}$ : number of RBC (type $k$ cells) generated after differentiation of (k-1)-type cell. (D) Steady state values according to Figure 1C depending on differentiation factors $D_{i}=p_{d}^{i}-p_{r}^{i}$. (E) Estimation of the RBC number at equilibrium, for the differentiation factors $D_{i}, i=2, \cdots, k^{-1}$, equal to $\mathrm{D}$ and the $\mu_{\mathrm{i}}$ probabilities equal to $1 .(F)$ Estimation of the division rate at equilibrium for each cell type based on BrdU data. $\mathrm{p}_{\mathrm{i}}^{\mathrm{BrdU}}$ : proportion at steadystate of BrdU+ i-type cells 20 hours after BrdU incorporation. (see Figure S1 and supplemental information in supplemental appendix).

\section{Figure 2: Analysis of Blood, Spleen and BM parameters after PHZ-mediated chemical}

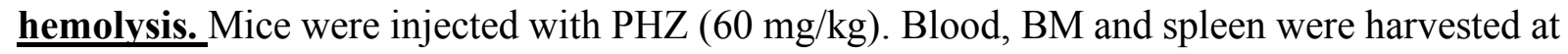
the indicated times. $(A) \mathrm{RBC}$ counts (x10\%/mouse) (orange line, biological values, black line, computed values). $(B)$ White blood cells (x10\%/mouse) and $(C)$ platelets (x106/mouse). $(D)$ Spleen morphological changes (photographs at day 0, 1, 3 and 5). (E) Total spleen cell number per mouse (x106/mouse). $(F)$ Spleen weight variations. $(G)$ Follow-up of total cell and MEP numbers for BM and Spleen (total bone marrow cells, blue line; total spleen cells, black line; Spleen MEP, Green line; BM MEP, orange line). Mean+/- SEM of at least 4 mice. ${ }^{*} \mathrm{p}<0.05$, $* * * \mathrm{p}<0.01$

Figure 3. Mathematical parameters required to Model stress Erythropoiesis _ $(A)$ Effects of $u_{r}$ and $u_{d}$ regulators on self-renewal and differentiation rates. $p_{r}^{i}(t)$ : self-renewal probability at $t$ time of $i$-type cells. $p_{d}{ }_{d}(t)$ : differentiation probability at $t$ time of i-type cells. $\left.u_{r}(t)\right)$ : selfrenewal regulation effect at $t$ time. $u_{d}(t)$ : Differentiation regulation effect at $t$ time $r_{i}$ : sensitivity of the i-type cell to $u_{r}$ regulator. $d_{i}$ sensitivity of the i-type cell to $u_{d}$ regulator. $(B)$ Dynamics of the $u_{r}$ and $u_{d}$ regulators. $d u_{r} / d t(t)$ : derivative of the $u_{r}$ function at $t$ time (similar notation for $\left.u_{d}\right) . u_{r}(t)$ and $u_{d}(t)$ : self-renewal and differentiation regulation effect at $t$ time. $a>0$ and $b>0$ : 
Michaelis-Menten's type constant of the $u_{r}$ and $u_{d}$ regulator. $m_{r}$ and $m_{d}$ : clearance rate of the $u_{r}$ and $\mathrm{u}_{\mathrm{d}}$ regulators. $(C)$. Regulation of the terminal erythroid production (from MEP to RBC). $2^{\mathrm{n}(\mathrm{t})}$ : number of RBC (k-type cells) generated after differentiation of a (k-1)-type cell at time $\mathrm{t}$. $c_{1}>1$ and $c_{2}>0$ : Hill constants of the regulated terminal mitosis of erythropoiesis. $\tau_{\mathrm{i}}{ }^{*}:$ steadystate division rate of $i$-type cells. $p_{r}^{i}$ : steady-state self-renewal probability of $i$-type cells. $p_{d}^{i}$ : steady-state differentiation probability of i-type cells. $\mu_{\mathrm{i}}$ : steady-state erythro-myeloid commitment probability of $\mathrm{i}$-type cells. $\mathrm{x}_{\mathrm{i}}(\mathrm{t}):$ number of $\mathrm{i}$-type cells at $\mathrm{t}$ time. $\mathrm{x}_{\mathrm{i}}{ }^{*}:$ steady-state number of i-type cells. $2^{n^{*}}:$ steady-state number of RBC (type $k$ cells) generated after differentiation of a (k-1)-type cell. $\mathrm{k}$ : number of compartments considered.

\section{Figure 4: Evolution of experimental and model parameters after PHZ-mediated chemical}

hemolysis. Blood Red Cell and bone marrow cell numbers per mouse (x10\%/mouse) assessed from experiments (red points: Red Blood cells, blue points: Total BM cells, green points: BM MEP, grey points: BM CMP, orange points: BM MPP, dark blue points: BM ST-HSC, brown points: BM LT-HSC). ${ }^{*} \mathrm{p}<0.05,{ }^{* *} \mathrm{p}<0.01 .(B)$. Experimental data generate values and standard errors from each time points. Evolution curves are deduced from the modeling and represent the number of cells corresponding to the $\mathrm{x}_{\mathrm{i}}{ }^{*}$ given in Table 2 (See supplemental information). 
A

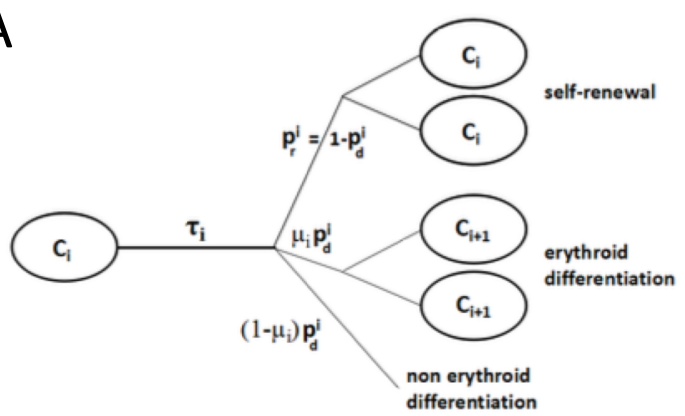

C

$\left\{\begin{array}{l}\frac{d x_{1}}{d t}(t)=\left(p_{r}^{1}-p_{d}^{1}\right) \tau_{1} x_{1}(t), \quad x_{1}(0)=x_{1}^{*} \\ \frac{d x_{2}}{d t}(t)=\mu_{1} \tau_{1} x_{1}(t)-\left(p_{d}^{2}-p_{r}^{2}\right) \tau_{2} x_{2}(t) \\ \text { for } i=3, \ldots, k-1, \\ \frac{d x_{i}}{d t}(t)=2 \mu_{i-1} p_{d}^{i-1} \tau_{i-1} x_{i-1}(t)-\left(p_{d}^{i}-p_{r}^{i}\right) \tau_{i} x_{i}(t) \\ \frac{d x_{k}}{d t}(t)=2^{n} p_{d}^{k-1} \tau_{k-1} x_{k-1}(t)-\tau_{k} x_{k}(t)\end{array}\right.$

E

$$
x_{k}^{*}=\frac{2^{n^{*}}(1+D)^{k-2} \tau_{1}^{*}}{D^{k-2} \tau_{k}^{*}} x_{1}^{*}
$$

B

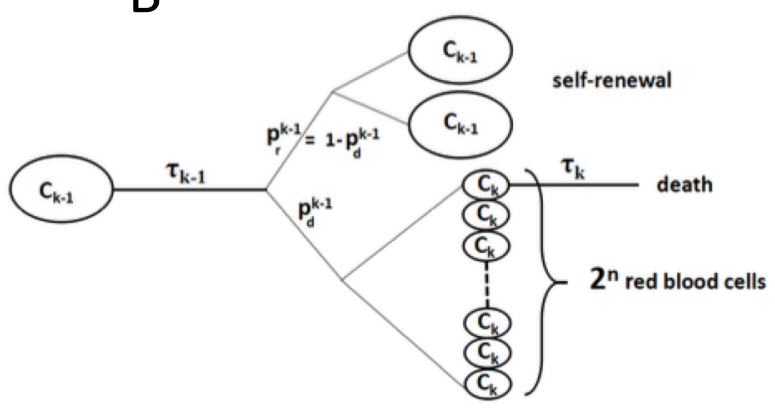

D

$$
\begin{gathered}
x_{2}^{*}=\frac{\mu_{1} \tau_{1}^{*} x_{1}^{*}}{D_{2} \tau_{2}^{*}} ; \ldots ; \\
x_{k-1}^{*}=\frac{\mu_{k-1}\left(1+D_{k-1}\right) \ldots \mu_{2}\left(1+D_{2}\right) \mu_{1} \tau_{1}^{*} x_{1}^{*}}{D_{k-1} \ldots D_{2} \tau_{k-1}^{*}} \\
x_{k}^{*}=\frac{2^{n^{*}} \mu_{k-1}\left(1+D_{k-1}\right) \ldots \mu_{2}\left(1+D_{2}\right) \mu_{1} \tau_{1}^{*} x_{1}^{*}}{D_{k-1} \ldots D_{2} \tau_{k}^{*}} \\
\text { For } i=2, \ldots, k-1, \quad x_{i}^{*}=\frac{\mu_{i-1}\left(1+D_{i-1}\right) \tau_{i-1}^{*}}{D_{i} \tau_{i}^{*}} x_{i-1}^{*}
\end{gathered}
$$

F $\tau_{i}^{*}=-\frac{24}{20} \log \left(1-p_{i}^{B r d U}\right)$ 
A

$$
\left\{\begin{array}{l}
p_{r}^{i}(t) \tau_{i}(t)=p_{r}^{i} \tau_{i}^{*}\left(\frac{u_{r}(t)}{u_{r}^{*}}\right)^{r_{i}} \\
\mu_{i}(t) p_{d}^{i}(t) \tau_{i}(t)=\mu_{i} p_{d}^{i} \tau_{i}^{*}\left(\frac{u_{d}(t)}{u_{d}^{*}}\right)^{d_{i}}
\end{array}\right.
$$

where $\left(r_{i}\right)_{i},\left(d_{i}\right)_{i}, u_{r}^{*}$ and $u_{d}^{*}$ are positive parameters.

C

$$
n(t)=n^{*} \frac{c_{1}}{1+\left(c_{1}-1\right)\left(\frac{x_{6}(t)}{x_{6}^{*}}\right)^{c_{2}}}
$$

B

$$
\begin{gathered}
\left\{\begin{array}{l}
\frac{d u_{r}(t)}{d t}=\frac{1}{a+y(t)}-m_{r} u_{r}(t) \\
\frac{d u_{d}(t)}{d t}=\frac{y(t)}{b+y(t)}-m_{d} u_{d}(t)
\end{array}\right. \\
\text { with } y(t)=\frac{x_{1}(t)}{x_{1}^{*}}+\frac{x_{2}(t)}{x_{2}^{*}}+\frac{x_{3}(t)}{x_{3}^{*}}+\frac{x_{4}(t)}{x_{4}^{*}}+\frac{x_{5}(t)}{x_{5}^{*}}
\end{gathered}
$$

Figure 3. Bonnet et al. 
100.000

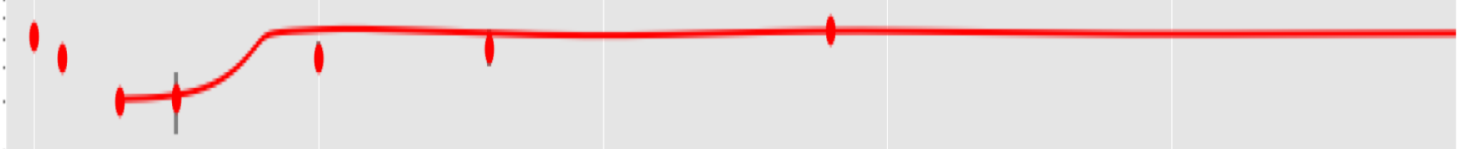

10.000

1.000

100

11,11

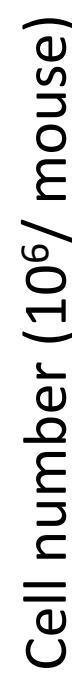

1

0.1

0.01

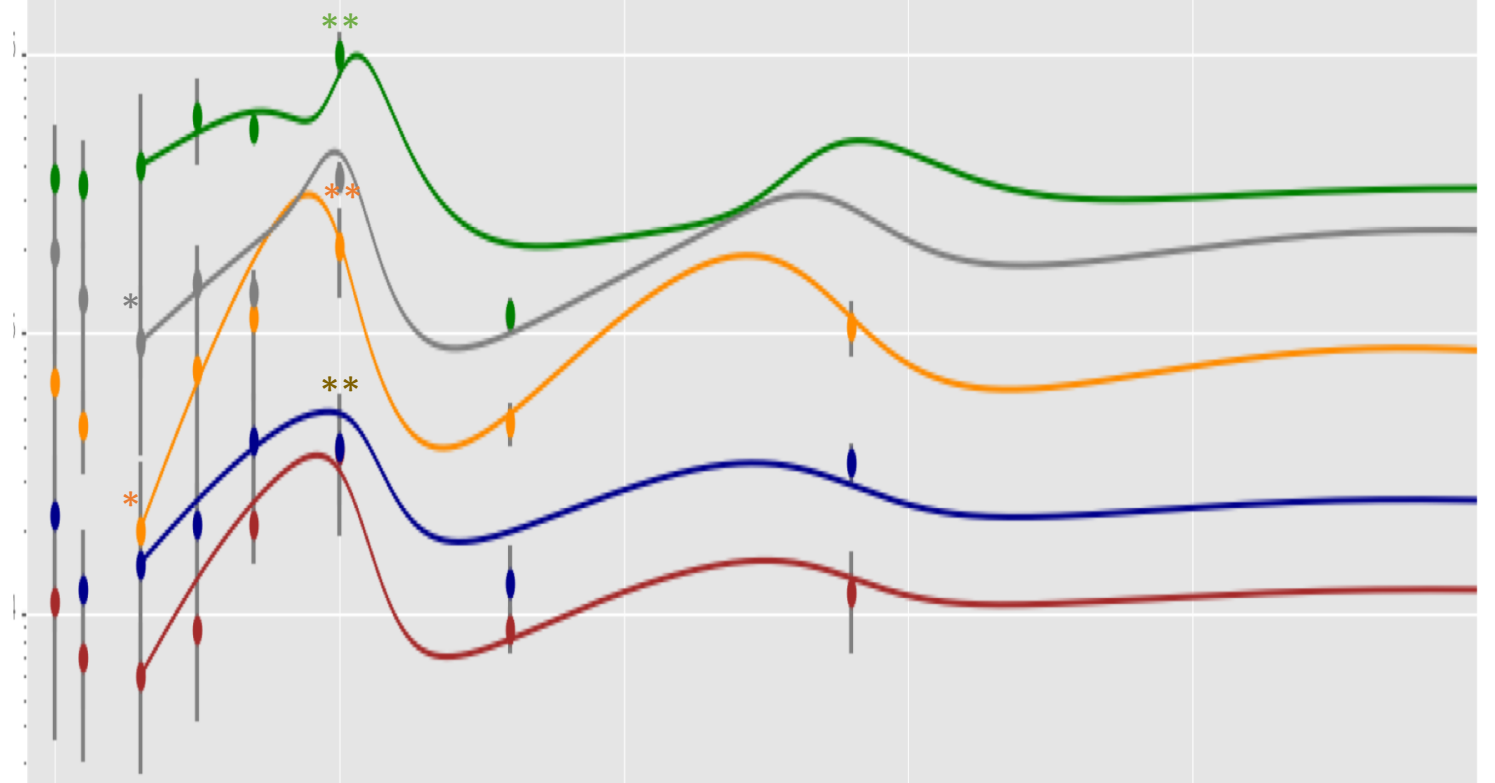

$\begin{array}{lllllllllll}0 & 5 & 10 & 15 & 20 & 25 & 30 & 35 & 40 & 45 & 50\end{array}$ 
STAR METHODS

Reagent or Resource

Source

Identifier

Antibodies

Biotin anti-mouse Lin Panel

Biolegend

133307

Ter-119, M1/70, RB6-8C5, 145-2C11, RA3-6B2

$\begin{array}{llr}\text { APC/Cy7 Streptavidin } & \text { Biolegend } & 405208 \\ \text { BV 510 }{ }^{\mathrm{TM}} \text { anti-mouse Ly-6A/E (Sca-1-) D7 } & \text { Biolegend } & 108129 \\ \text { BV421 anti-mouse CD135 A2F10 } & \text { Biolegend } & 135315 \\ \text { BV711 anti-mouse CD48 HM48-1 } & \text { Biolegend } & 103439 \\ \text { PE/Cy7 anti-mouse CD150 TC15-12F12.2 } & \text { Biolegend } & 115914 \\ \text { BB700 Anti-Mouse CD117 (PerCP) 2B8 } & \text { BD Pharmingen } & 566414 \\ \text { BV786 Anti-Mouse CD16/CD32 2.4G2 } & \text { BD Pharmingen } & 740851 \\ \text { Alexa Fluor }{ }^{6} \text { 647 anti-Mouse CD34 Ram34 } & \text { BD Pharmingen } & 560230 \\ \text { Alexa Fluor 488 anti-BrdU Antibody } & \text { Biolegend } & 364105 \\ \text { FITC anti-mouse CD45.1 A20 } & \text { Biolegend } & 110705 \\ \text { PE anti mouse CD45.2 104 } & \text { Biolegend } & 109808\end{array}$

Chemicals, Peptides, and Recombinant Proteins

PHZ (Phenylhydrazine)

Sigma-Aldrich

P26252

Critical Commercial Assays

Zombie UV fixable viability kit

Ozyme

BLE423107

BD Horizon Brilliant staining buffer

BD Pharmingen

563794

Ultracomp ebeads

Life Technologies

$01-2222-42$

Rainbow Calibration Particles (8 - PEaks),

3.0-3.4 mm SPHERO Particles

BD Pharmingen

559123

BD Pharmingen BrdU Flow Kit

BD Pharmingen

557892

FITC Annexin V Apoptosis Detection Kit

BD Pharmingen

559763

ACK Lysing Buffer, Quality Biological

VWR

10128-802

Experimental Models: Organisms/Strains

C57BL/6J

Janvier (Le Genest, France) 
B6.SJL-Ptprc ${ }^{\mathrm{a} P e p c}$ /BoyCrl Congenic (Ly5.1 mice) Janvier (Le Genest, France)

\section{Software and Algorithms}

Diva software

Beckman

Kakuza software

Beckman

Covariance matrix adaptative in Evolution algorithm (CMAES) Python language 


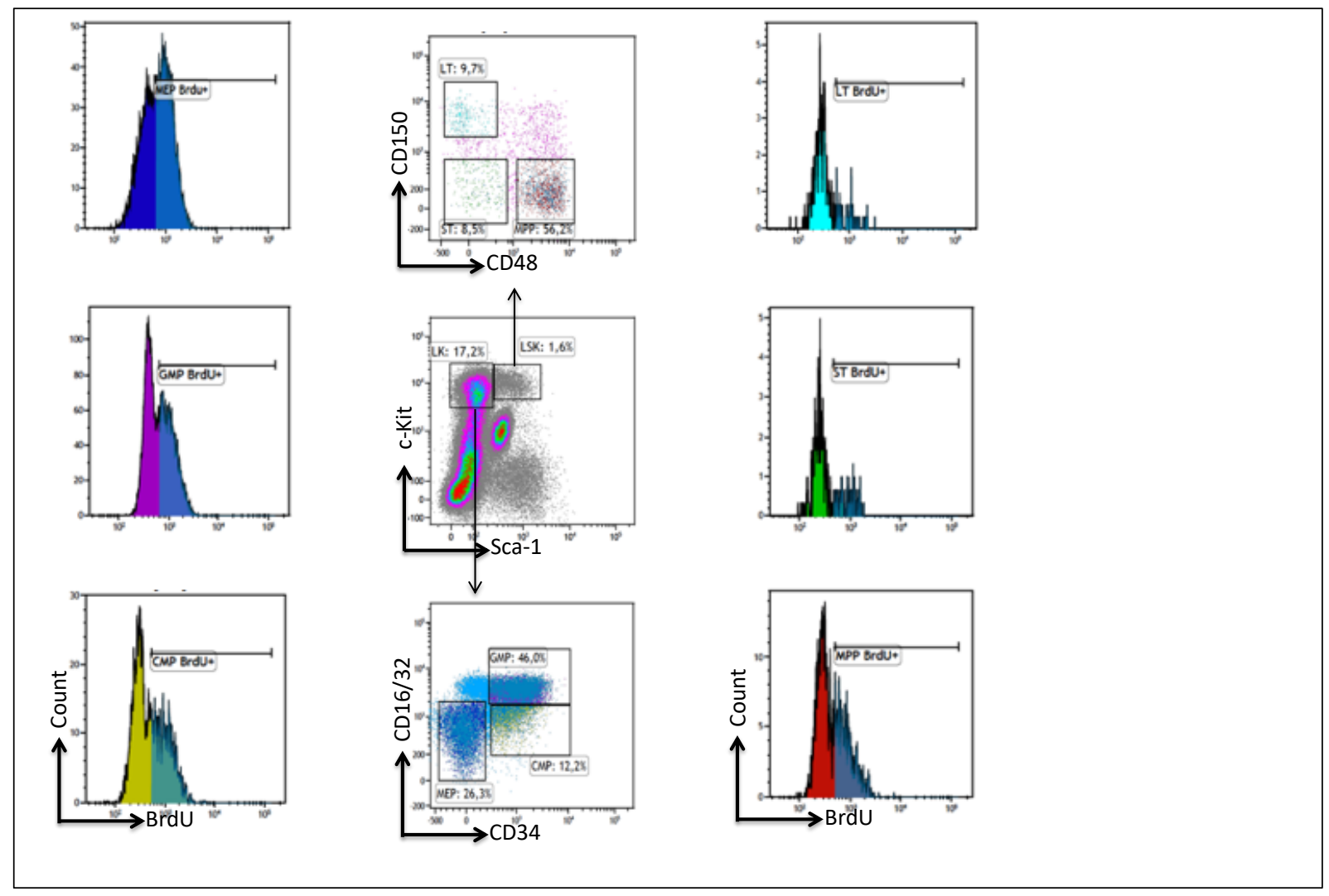

Figure S1: Single staining 9-parameter analysis of mouse bone marrow cells. After RBC lysis, cellular debris or doublets were discriminated from single cells by analyzing the side scatter area and width signals. Single cells were then stained with the life/dead discriminator (Zombie), and alive cells were then plotted for lineage markers (CD3e, CD11b, B220, Gr1, and Ter119). Lineage negative cells were analyzed for c-Kit and Sca-1 to define the LSK and LS$\mathrm{K}$ cell populations. LS-K cells were discriminated by expression of CD16/32 and CD34 to identify GMP, CMP and MEP populations. LSK cells were discriminated by expression of CD150 and CD48 to identify LT-HSC, ST-HSC and MPP populations. BrdU incorporation was assessed in all these populations. 


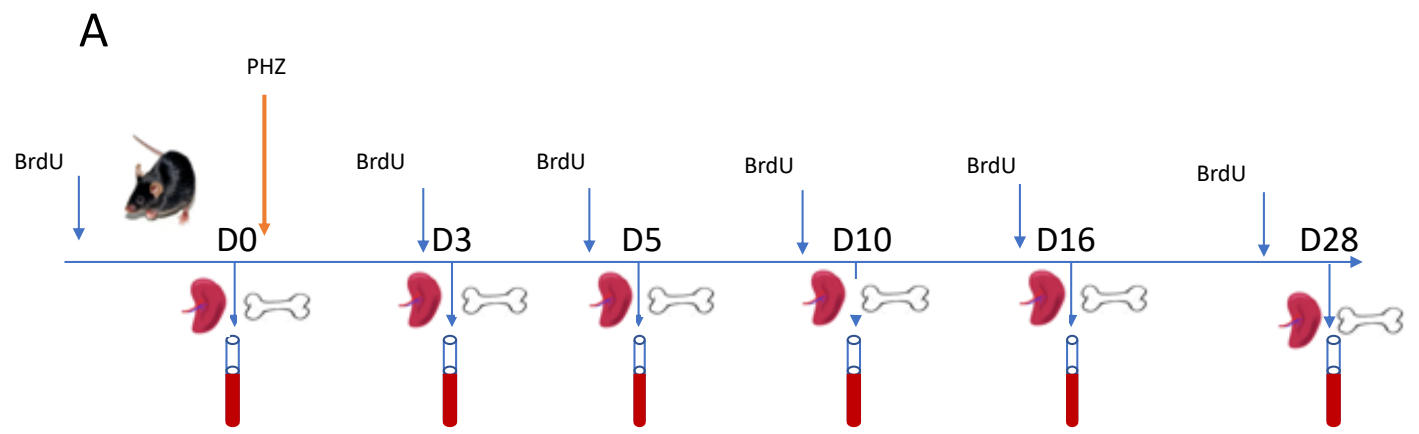

B

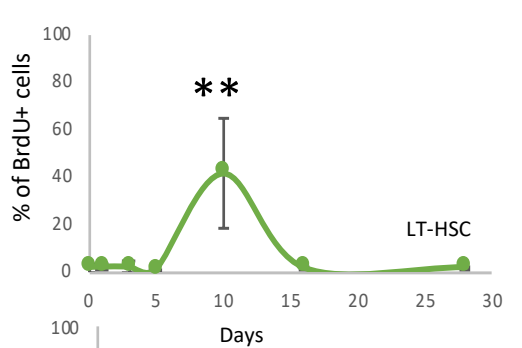

C

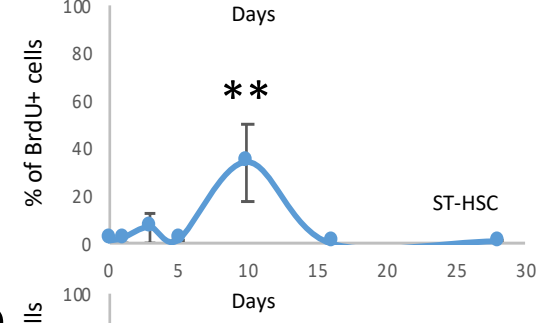

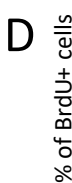

$E$
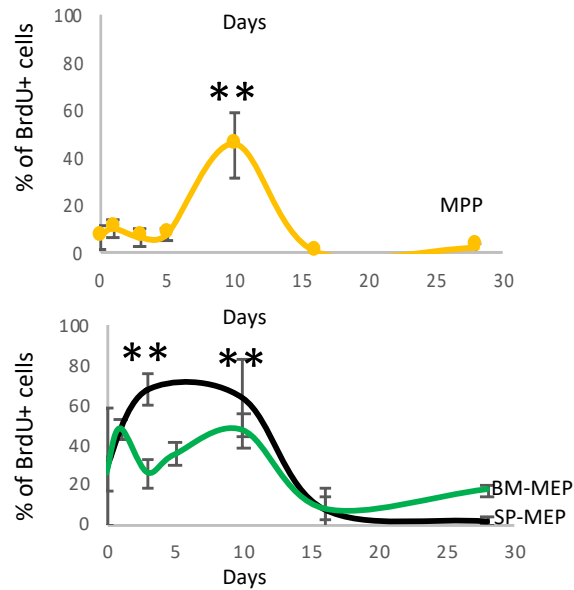

$\mathrm{F}$

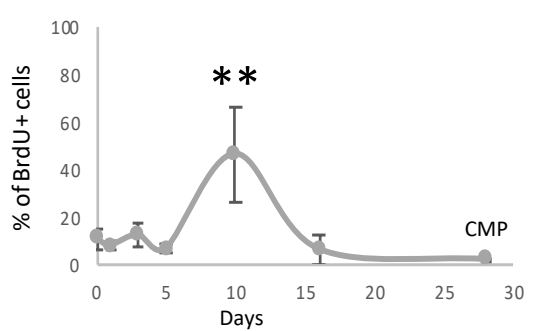

Figure S2: Analvsis of BrdU incorporation in HSPCs at different time points after PHZ

administration. (A) Summary scheme of PHZ treatment. $(B-F)$ Percentage of $\mathrm{BrdU}^{+}$cells $16 \mathrm{~h}$ after intraperitoneal BrdU injection. (B) BM LT-HSC, $(C)$ BM ST-HSC, $(D)$ BM MPP, $(E)$ MEP from BM (green) and spleen (black), $(F)$ BM CMP. ${ }^{* *} \mathrm{p}<0,01$. (n=5). 


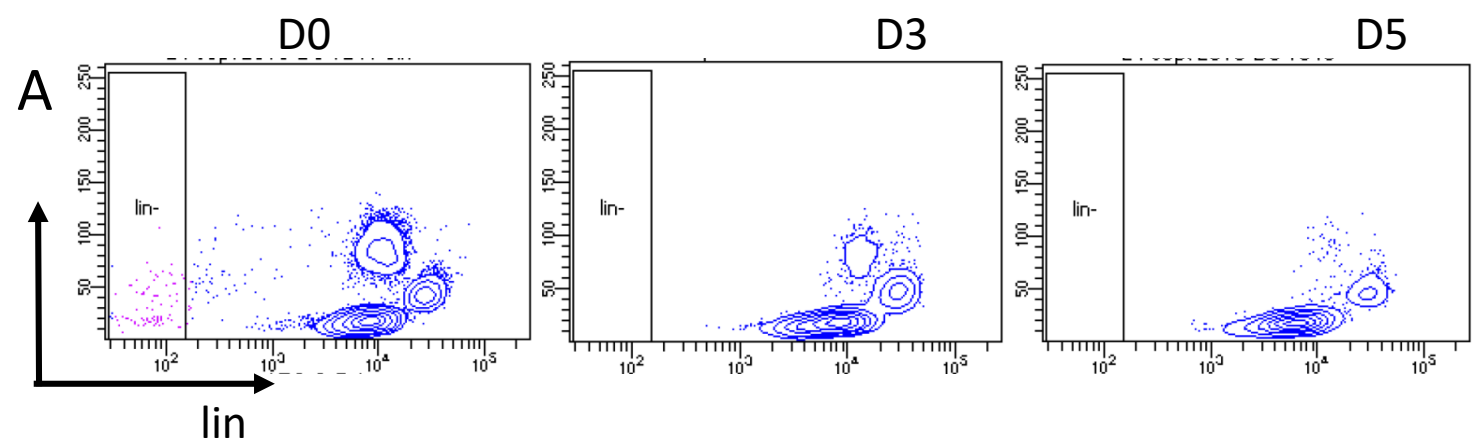

B
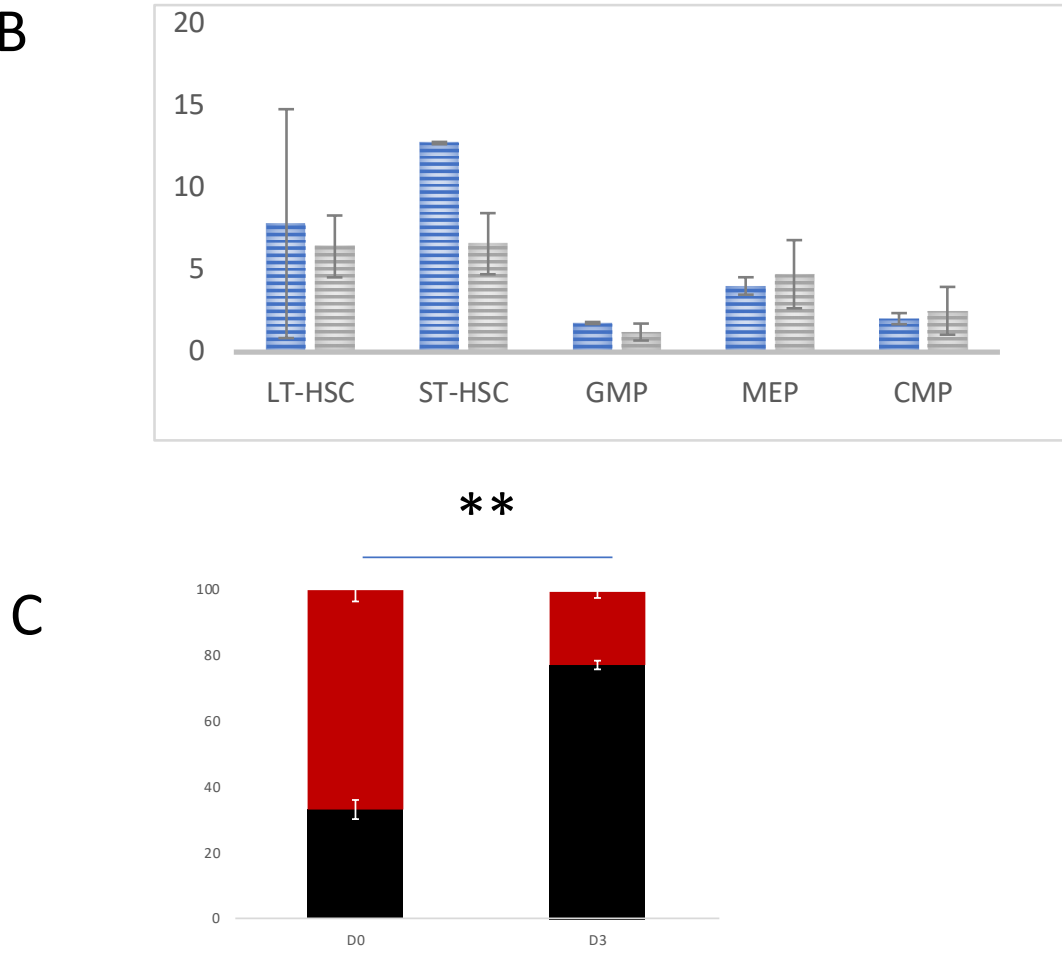

Figure S3: Analysis of peripheral blood, BM and spleen after PHZ administration. $(A)$

Cytometric analysis to detect the presence of lin- cells in the peripheral blood. (B) Cytometric analysis of apoptosis (AnnexinV positive cells) in the different progenitor compartments at day 3 after PHZ treatment. (C) Three days after PHZ administration, lethally irradiated C57BL/6Ly5.1 mice received 106 $\mathrm{BM}$ cells from PHZ-treated C57Bl/6 (Ly5.2) mice, in competition with the same amount of BM cells from Ly5.1 mice. Presence of CD45.2+ PB cells of engrafted 
mice was assessed 3 months later by flow cytometry. Data are expressed as mean \pm SEM. **P $<.01 ;$ (Student $\mathrm{t}$ test).

\section{SUPPLEMENTAL DATA}

\section{1- Complementary informations for Figure $1 F$.}

Table 1 presents the $\%$ of $\mathrm{BrdU}^{+}$cells of each compartment at the steady state, which corresponds to the proportion of cells having performed at least one division during 20 hours . Here, we will relate these informations to the steady-state division rates of each cell type: $\tau_{i}^{*}$. Before BrdU injection, the system is at equilibrium and all cells are unlabeled by BrdU. The numbers of BrdU+ and unlabeled i-type cells at time $t$ of the experiment are denoted by $\mathrm{N}_{\mathrm{i}} \mathrm{m}(\mathrm{t})$ and $\mathrm{N}_{\mathrm{i}}(\mathrm{t})$. Then $\mathrm{N}_{\mathrm{i}}^{\mathrm{m}}(0)=0$ and $\mathrm{N}_{\mathrm{i}}(0)=\mathrm{x}_{\mathrm{i}}{ }^{*}$.

During the experiment, when an unlabeled cell of $i$ type divides, it becomes BrdU+. Thus the dynamics of unlabeled i-type cell number is expressed as an exponential decrease at $\tau i^{*}$ rate. Throughout the experiment, the system is considered to be at steady state. Therefore, for any $\mathrm{i}$ $=1, \ldots, \mathrm{k}-1$, and for any $\mathrm{t} \in[0,24 \mathrm{~h}], \mathrm{N}_{\mathrm{i}}{ }^{\mathrm{m}}(\mathrm{t})+\mathrm{N}_{\mathrm{i}}(\mathrm{t})=\mathrm{x}_{\mathrm{i}}{ }^{*}$. The formula in Figure $1 \mathrm{~F}$ is then deduced.

\section{2- Calibration of the regulated-erythropoiesis model}

Parameters of the regulated model were calibrated from data of the 6 population sizes dynamics after PHZ induced hemolysis. In order to model the return to the equilibrium (given in Figure 4B), we considered day 3 as the initial time. Hence initial conditions of the model are given by $: \mathrm{x}_{1}($ day 3$)=0.006 \cdot 10^{6}$ cells $/$ mouse, $\mathrm{x}_{2}($ day 3$)=0.0152 .10^{6}$ cells $/$ mouse

$\mathrm{x}_{3}($ day 3$)=0.02 .10^{6}$ cells $/$ mouse, $\mathrm{x}_{4}($ day 3$)=0.093 .10^{6}$ cells $/$ mouse 
$\mathrm{x}_{5}($ day 3$)=0.395 .10^{6}$ cells $/$ mouse, $\mathrm{x}_{6}($ day 3$)=0.94 .10^{10}$ cells $/$ mouse

Using a stochastic optimization algorithm based on a CMA-ES method (Covariance Matrix Adaptation Matrix in Evolution Strategy), developed on Python by the INRIA team RandOpt (Hansen and Ostermeier, 2001) and least-squares cost function, we minimized the discrepancy between in silico simulated and experimental data. Results were summarized in Table 3. In such algorithms, identifiability is numerically accepted when identical results for a large number of independent runs are obtained.

\section{References}

Hansen, N., and Ostermeier, A. (2001). Completely derandomized self-adaptation in evolution strategies. Evolutionary Computation 9, 159-195. 